\title{
Age, waist circumference, and blood pressure are associated with skin microvascular flow motion: The Maastricht Study
}

Citation for published version (APA):

Muris, D. M. J., Houben, A. J. H. M., Kroon, A. A., Henry, R. M. A., van der Kallen, C. J. H., Sep, S. J. S., Koster, A., Dagnelie, P. C., Schram, M. T., \& Stehouwer, C. D. A. (2014). Age, waist circumference, and blood pressure are associated with skin microvascular flow motion: The Maastricht Study. Journal of Hypertension, 32(12), 2439-2449. https://doi.org/10.1097/HJH.0000000000000348

Document status and date:

Published: 01/12/2014

DOI:

10.1097/HJH.0000000000000348

Document Version:

Publisher's PDF, also known as Version of record

Document license:

Taverne

Please check the document version of this publication:

- A submitted manuscript is the version of the article upon submission and before peer-review. There can be important differences between the submitted version and the official published version of record.

People interested in the research are advised to contact the author for the final version of the publication, or visit the DOI to the publisher's website.

- The final author version and the galley proof are versions of the publication after peer review.

- The final published version features the final layout of the paper including the volume, issue and page numbers.

Link to publication

\footnotetext{
General rights rights.

- You may freely distribute the URL identifying the publication in the public portal. please follow below link for the End User Agreement:

www.umlib.nl/taverne-license

Take down policy

If you believe that this document breaches copyright please contact us at:

repository@maastrichtuniversity.nl

providing details and we will investigate your claim.
}

Copyright and moral rights for the publications made accessible in the public portal are retained by the authors and/or other copyright owners and it is a condition of accessing publications that users recognise and abide by the legal requirements associated with these

- Users may download and print one copy of any publication from the public portal for the purpose of private study or research.

- You may not further distribute the material or use it for any profit-making activity or commercial gain

If the publication is distributed under the terms of Article $25 \mathrm{fa}$ of the Dutch Copyright Act, indicated by the "Taverne" license above, 


\title{
Original Article
}

\section{Age, waist circumference, and blood pressure are associated with skin microvascular flow motion: The Maastricht Study}

\author{
Dennis M.J. Muris ${ }^{a, b}$, Alfons J.H.M. Houben ${ }^{a, b}{ }^{,}$Abraham A. Kroon $^{a, b}$, Ronald M.A. Henry, ${ }^{a, b}$, \\ Carla J.H. van der Kallen ${ }^{a, b}$, Simone J.S. Sep ${ }^{a, b}$, Annemarie Koster ${ }^{c, d}$, Pieter C. Dagnelie ${ }^{d, e}$, \\ Miranda T. Schram ${ }^{a, b}$, and Coen D.A. Stehouwer ${ }^{a, b}$
}

\begin{abstract}
Objective: Skin microvascular flow motion (SMF) - blood flow fluctuation attributed to the rhythmic contraction and dilation of arterioles - is thought to be an important component of the microcirculation, by ensuring optimal delivery of nutrients and oxygen to tissue and regulating local hydraulic resistance. There is some evidence that SMF is altered in obesity, type 2 diabetes mellitus, and hypertension. Nevertheless, most studies of SMF have been conducted in highly selected patient groups, and evidence how SMF relates to other cardiovascular risk factors is scarce. Therefore, the aim of the present study was to examine in a population-based setting which cardiovascular risk factors are associated with SMF.
\end{abstract}

Methods: We measured SMF in 506 participants of the Maastricht Study without prior cardiovascular event. SMF was investigated using Fourier transform analysis of skin laser Doppler flowmetry at rest within five frequency intervals in the $0.01-1.6-\mathrm{Hz}$ spectral range. The associations with SMF of the cardiovascular risk factors age, sex, waist circumference, total-to-high-density lipoprotein cholesterol, fasting plasma glucose, 24-h SBP, and cigarette smoking were analysed by use of multiple linear regression analysis.

Results: Per 1 SD higher age, waist circumference and 24-h SBP, SMF was 0.16 SD higher [95\% confidence interval $(\mathrm{Cl}) 0.07,0.25 ; P<0.001),-0.14$ SD lower $(95 \%$ $\mathrm{Cl}-0.25,-0.04 ; P=0.01)$, and $0.16 \mathrm{SD}$ higher $(95 \% \mathrm{Cl}$ $0.07,0.26 ; P<0.001)$, respectively, in fully adjusted analyses. We found no significant associations of sex, fasting plasma glucose levels, total-to-high-density lipoprotein cholesterol ratio, or pack years of smoking with SMF.

Conclusion: Age and 24-h SBP are directly, and waist circumference is inversely associated with SMF in the general population. The exact mechanisms underlying these findings remain elusive. We hypothesize that flow motion may be an important component of the microcirculation by ensuring optimal delivery of nutrients and oxygen to tissue and regulating local hydraulic resistance not only under physiological conditions but also under pathophysiological conditions when microcirculatory perfusion is reduced, such as occurs with ageing and higher blood pressure. In addition, obesity may result in an impaired flow motion with negative effects on the delivery of nutrients and oxygen to tissue and local hydraulic resistance.

Keywords: blood flow regulation, microcirculation, risk factors

Abbreviation: SMF, skin microvascular flow motion

\section{INTRODUGTION}

$\mathrm{M}$ icrovascular vasomotion, that is rhythmic changes in (precapillary) arteriolar diameter, is thought to be an important component of microvascular function [1]. In fact, these rhythmic oscillations regulate microvascular flow distribution so that various tissue regions are intermittently perfused $[1,2]$. Indeed, theoretical and experimental studies demonstrate that an increase in vasomotion can increase total blood flow by 40-60\% [3,4]. In addition, when active and passive vessels with the same average diameter are compared, active vessels have a lower vascular resistance (according to Poiseuille's law) [5,6], that is, vasomotion decreases arterial pressure by $20 \%$ [7]. Thus, vasomotion may be an important component of the microcirculation by ensuring optimal delivery of nutrients and oxygen to tissue and regulating local hydraulic resistance (i.e. resistance of the microcirculatory bed to blood flow) $[1,5,8]$. The rhythmic changes in arteriolar diameter caused by vasomotion produce periodical fluctuations of flow known as microvascular flow motion [8]. Skin microvascular flow motion (SMF) can easily be assessed using

Journal of Hypertension 2014, 32:2439-2449

${ }^{a}$ Department of Internal Medicine, Maastricht University Medical Centre (MUMC+), ${ }^{\mathrm{b}}$ Cardiovascular Research Institute Maastricht (CARIM), 'Department of Social Medicine, ${ }^{\mathrm{d}}$ CAPHRI School for Public Health and Primary Care and eDepartment of Epidemiology, Maastricht University, Maastricht, the Netherlands

Correspondence to Alfons J.H.M. Houben, PhD, Maastricht University Medical Centre, Department of Internal Medicine, P.O. Box 5800, 6202 AZ, Maastricht, the Netherlands. E-mail: b.houben@maastrichtuniversity.nl

Received 26 June 2014 Revised 16 July 2014 Accepted 16 July 2014

J Hypertens 32:2439-2449 (C) 2014 Wolters Kluwer Health | Lippincott Williams \& Wilkins.

DOI:10.1097/HJH.0000000000000348 
laser-Doppler flowmetry (LDF). In-vivo measurements of SMF show a broad spectrum of oscillation frequencies, with high-frequency oscillations originating from the cardiac and respiratory cycles, and low-frequency oscillations origination from the endothelial, neurogenic, and myogenic cycles [8-10].

Central obesity and a sedentary lifestyle are important causes of type 2 diabetes mellitus (T2DM) and hypertension, respectively [11]. However, how obesity leads to T2DM and hypertension is incompletely understood. We and others have advanced the hypothesis that microvascular dysfunction may contribute both to the development of T2DM - by impairing the timely access of glucose and insulin to their target tissues - and to the development of hypertension - by increasing vascular resistance [12]. In addition, it has been suggested that obesity is a primary cause of microvascular dysfunction [13]. Therefore, microvascular dysfunction may be an intermediate step linking central obesity to T2DM and hypertension [14].

There is some evidence supporting the hypothesis that SMF, as an important component of microvascular function, is altered in obesity, T2DM, and hypertension [1,15-18]. Nevertheless, most studies on SMF have been conducted in small numbers of highly selected patients. Hence, whether the differences found in these studies can be translated to the general population is unknown. In addition, evidence on whether and to what extent SMF relates to other cardiovascular risk factors, such as smoking and cholesterol levels, is scarce [19].

Therefore, the aim of the present study was to examine in a population-based setting which cardiovascular risk factors are associated with SMF. In addition, we investigated whether any such associations are similar in a healthy subpopulation (free of obesity, hypertension, T2DM, and medication use).

\section{METHODS}

\section{Study population}

In this study, we used data from The Maastricht Study, an observational prospective population-based cohort study. The rationale and methodology have been described previously [20]. In brief, the study focuses on the cause, pathophysiology, complications and comorbidities of T2DM and is characterized by an extensive phenotyping approach. Eligible for participation were all individuals aged between 40 and 75 years and living in the southern part of the Netherlands. Participants were recruited through mass media campaigns and from the municipal registries and the regional Diabetes Patient Registry via e-mails. Recruitment was stratified according to known T2DM status for reasons of efficiency. The present study includes crosssectional data from the first 866 participants, who completed the baseline survey between November 2010 and March 2012. The examinations of each participant were performed within a time window of 3 months. The study has been approved by the Institutional Medical Ethical Committee (NL31329.068.10) and the Netherlands Health Council under the Dutch 'Law for Population Studies' (Permit 131088-105234-PG). All participants gave written informed consent.

\section{Skin microvascular flow motion measurements}

All participants were asked to refrain from smoking and caffeine $3 \mathrm{~h}$ before the measurements. A light meal [breakfast and (or) lunch], which was low in fat content, was allowed prior to the start of the measurements. LDF measurements were performed in a quiet, climatecontrolled room $\left(\mathrm{T}=24^{\circ} \mathrm{C}\right)$ with participants in the supine position, as previously described [1].

Cutaneous blood perfusion was measured by means of a laser-Doppler system (Periflux 5000; Perimed, Stockholm, Sweden), equipped with a thermostatic laser-Doppler probe (PF 457; Perimed) at the dorsal side of the wrist of the left hand. Since flow motion has predominantly been observed in participants with a skin temperature above $29.3^{\circ} \mathrm{C}$ [3], the laser-Doppler probe was set at $30^{\circ} \mathrm{C}$. The LDF output was recorded for $25 \mathrm{~min}$ with a sample rate of $32 \mathrm{~Hz}$, which gives a semi-quantitative assessment of skin microvascular blood perfusion expressed in arbitrary perfusion units (i.e. the product of the velocity and concentration of moving red blood cells [21]). LDF measurements from the skin reflect perfusion in predominantly arterioles and venules [22].

Fast-Fourier transform algorithm was performed by means of Perisoft dedicated software (PSW version 2.50; Perimed) to measure the power density of the LDF oscillation. The frequency spectrum between 0.01 and $1.6 \mathrm{~Hz}$ was divided into five SMF components: endothelial, 0.01$0.02 \mathrm{~Hz}$; neurogenic, $0.02-0.06 \mathrm{~Hz}$; myogenic, $0.06-0.15 \mathrm{~Hz}$; respiratory, $0.15-0.40 \mathrm{~Hz}$; and heart beat, $0.40-1.60 \mathrm{~Hz}$ [10]. In addition, total SMF energy was obtained by the sum of the power density values of the total frequency spectrum.

\section{Definition of cardiovascular risk factors}

Cardiovascular risk factors were adapted from the Framingham risk score [23], and included the following: age, sex, waist circumference, fasting plasma glucose, total-to-highdensity lipoprotein (HDL) cholesterol ratio, 24-h SBP, and pack years of smoking.

\section{Measurements of cardiovascular risk factors}

Medical history, history of cardiovascular disease, medication use, and smoking behaviour were assessed by questionnaire [20]. Weight, height, waist circumference, glycated hemoglobin (HbA1c), glucose levels, total and HDL cholesterol, and triglycerides were determined as described elsewhere [20].

To determine glucose metabolism, all participants (except those who used insulin) underwent a standardized 2-h 75 g oral glucose tolerance test (OGTT) after an overnight fast. For safety reasons, participants with a fasting glucose level above $11.0 \mathrm{mmol} / \mathrm{l}$, as determined by a finger prick, did not undergo the OGTT. For these individuals $(n=13)$, fasting glucose level and information about diabetes medication use were used to determine glucose metabolism status. Glucose metabolism was defined according to the WHO 2006 criteria into normal glucose metabolism, impaired fasting glucose (IFG), impaired glucose tolerance (IGT), and T2DM [24]. Additionally, individuals without type 1 diabetes mellitus (T1DM) and on diabetes medication were considered as having T2DM [20].

Ambulatory blood pressure (BP) was measured with ambulatory 24-h BP monitoring (WatchBP O3; Microlife 
AG, Switzerland). Cuffs were applied to the participants' non-dominant arm. Measurements were programmed for every $15 \mathrm{~min}$ during daytime $(0800-2300 \mathrm{~h})$ and every 30 min during the night $(2300-0800 \mathrm{~h})$, for a total of $24 \mathrm{~h}$. As quality criteria, mean 24-h BP measurements were only calculated if there were more than 14 valid measurements at daytime and more than seven valid measurements at night, based on the recommendations of the British Hypertension Society [25]. To classify BP, we applied the guidelines as suggested by the Joint National Committee on Prevention, Detection, Evaluation, and Treatment of High Blood Pressure [26]. Hypertension was defined as 24-h SBP at least $135 \mathrm{mmHg}$, 24-h DBP at least $85 \mathrm{mmHg}$, and/or the use of antihypertensive medication.

Pack-years of smoking was defined as one packet (20 cigarettes) per day, smoked over a course of 1 year.

\section{Assessment of sensory neuropathy}

Vibration perception threshold (VPT) was measured as a marker of peripheral neuropathy. VPT was assessed using a hand-held neurothesiometer (Horwell Scientific Laboratory Supplies, Nottingham, UK). After a test procedure on the patient's elbow, VPT was tested three times at the distal phalanx of the hallux of the right and left foot. The minimum VPT at which the patient was aware of vibration sensation was recorded to the nearest $0.5 \mathrm{~V}$, starting from $0.0 \mathrm{~V}$ with increasing stimulation. The mean of the three measurements for the least sensitive foot was used in further analyses [27,28]. Peripheral sensory neuropathy (PSN) was defined as VPT at least $25 \mathrm{~V}$ [28].

\section{Statistical analysis}

All statistical analyses were performed with the use of the Statistical Package for Social Sciences (version 20.0; IBM, Chicago, Illinois, USA). We used standardized multiple linear regression analysis to evaluate the association of cardiovascular risk factors with both total SMF energy and the energy contribution of the five SMF components. All associations were adjusted for the other cardiovascular risk factors and diabetes status. On the basis of an a priori sample size calculation [29] with a small effect size $\left(f^{2}=0.03\right)$, we estimated that a sample size of approximately 485 participants was sufficient for our analysis. Finally, by design, the study population was enriched with T2DM participants. Therefore, we investigated whether these associations differed by T2DM status by adding interaction terms in our models (i.e. the product of the cardiovascular risk factor and T2DM). Variables with a skewed distribution were log-transformed for further analyses.

Data are expressed as standardized regression coefficients $(\mathrm{s} \beta)$ with their $95 \%$ confidence intervals (95\% CIs). A $P$ value less than 0.05 was considered statistically significant.

\section{RESULTS}

From the initial 866 participants included in this study, we excluded four participants with T1DM. In the remaining 862 participants, LDF data were available in 746 participants; the reason for the missing data was a defective LDF system $(n=78)$ and unsatisfactory LDF measurements (i.e. LDF recordings less than $10 \mathrm{~min}, n=38$ ). In addition, to avoid treatment-induced changes in microvascular function, we excluded participants with a prior cardiovascular event $(n=152)$. In the remaining 594 participants, all variables were available in the 506 participants. Data were missing on 24-h BP measurements $(n=47)$, pack-years of smoking $(n=36)$, cholesterol levels $(n=4)$, and waist circumference $(n=1)$ (Fig. 1). In addition, we selected a healthy subpopulation of participants who were free of: impaired glucose metabolism (IGM) or T2DM; hypertension; glucose-lowering medication, antihypertensive medication, and lipid-modifying medication use; and BMI at least $30 \mathrm{~kg} / \mathrm{m}^{2}$. Complete data for this healthy subpopulation were available in 193 participants (Fig. 1).

\section{General characteristics}

Baseline characteristics of the study population are shown in Table 1. The study population included $260(51.4 \%)$ men, 73 (14.4\%) current smokers, 120 participants (23.7\%) with T2DM, and 189 participants (37.4\%) with hypertension. The healthy subpopulation included $80(41.4 \%)$ men and 28 (14.5\%) current smokers. In addition, Table 1 shows that, when compared with participants in the lowest tertile of SMF, those in the middle and highest tertiles had a higher age and higher BP values. The median value of total SMF energy was 14.5 (inter-quartile range 9.1-21.4) in the study population and $13.6(7.8-22.1)$ in the healthy subpopulation (Table 2$)$.

\section{Associations of age with total skin microvascular flow motion energy and the skin microvascular flow motion components}

Age was associated with a higher total SMF energy; per SD higher age ( 8.5 years) total SMF energy was $0.16 \mathrm{SD}(95 \% \mathrm{CI}$ $0.07,0.25 ; P<0.001$ ) higher (Fig. 2). Age was not significantly associated with the energy contribution of the endothelial, neurogenic, and myogenic component, but was associated with a higher energy contribution of the respiratory and heart beat component $[\mathrm{s} \beta 0.24 \mathrm{SD}(0.15,0.33)$; $P<0.001$ and $\mathrm{s} \beta 0.20$ SD $(0.11,0.29) ; P<0.001$, respectively] (Fig. 3). We found similar results when the frequency components were divided into a low $(0.01-0.15 \mathrm{~Hz})$ and high $(0.15-1.60 \mathrm{~Hz})$ frequency component; age was not significantly associated with the energy contribution of the low-frequency component [s $\beta \quad 0.02$ SD $(-0.08,0.11)$; $P=0.73$, but was associated with a higher energy contribution of the high-frequency component [s $\beta 0.21$ SD $(0.12$, $0.30) ; P<0.001]$. These results did not materially change when analyses were restricted to the healthy subpopulation (Figs. 4 and 5), although the association of a higher age with total SMF energy and the energy contribution of the heart beat component became somewhat weaker and borderline significant [s $\beta 0.13 \mathrm{SD}(-0.02,0.27) ; P=0.09$ and $\mathrm{s} \beta 0.13 \mathrm{SD}$ $(-0.02,0.28) ; P=0.09$, respectively].

\section{Associations of waist circumference with total skin microvascular flow motion energy and the skin microvascular flow motion components}

Waist circumference was associated with a lower total SMF energy; per SD higher waist circumference $(13.0 \mathrm{~cm})$ total SMF energy was -0.14 SD $(-0.25,-0.04 ; P=0.01)$ lower (Fig. 2). In addition, waist circumference was associated with 


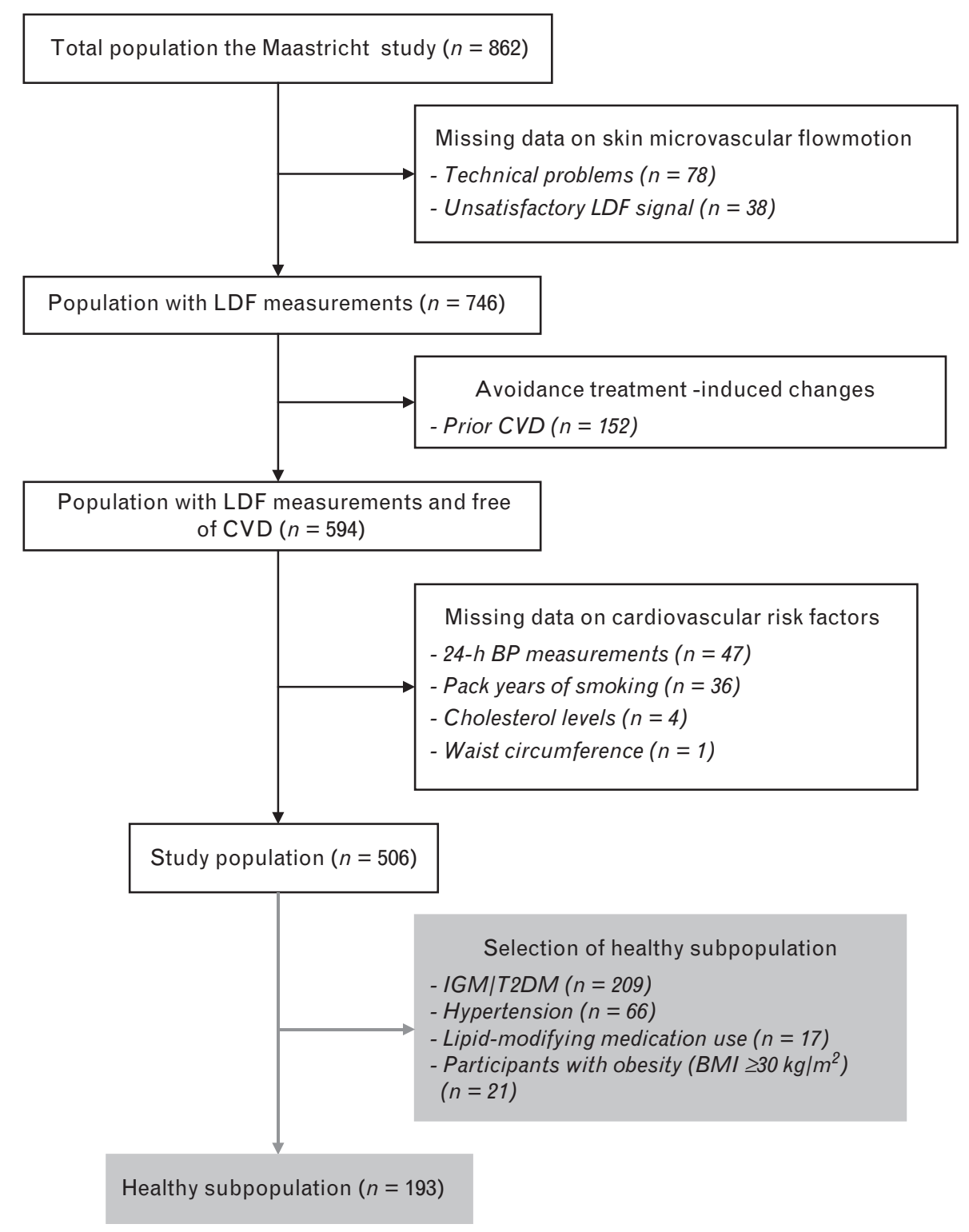

FIGURE 1 Flow diagram.

a lower energy contribution of all the five frequency components (Fig. 3). We found similar results with the low and high-frequency component; waist circumference was significantly associated with a lower energy contribution of the low as well as the high-frequency component. Restriction of these analyses to the healthy subpopulation showed similar results (Figs 4 and 5), although the association of a higher waist circumference with the energy contribution of the endothelial, neurogenic, and heart beat component became somewhat weaker and borderline significant $[\mathrm{s} \beta-0.17 \mathrm{SD}$ $(-0.34,0.01) ; P=0.07, \mathrm{~s} \beta-0.16 \mathrm{SD}(-0.35,0.02) ; P=0.09$, and $\mathrm{s} \beta-0.15 \mathrm{SD}(-0.33,0.03) ; P=0.10$, respectively].

\section{Associations of 24-h SBP with total skin microvascular flow motion energy and the skin microvascular flow motion components}

Twenty-four-hour SBP was associated with a higher total SMF energy; per SD higher 24-h SBP (12 mmHg) total SMF energy was $0.16 \mathrm{SD}(0.07,0.26 ; P<0.001)$ higher (Fig. 2). In addition, 24-h SBP was associated with a higher energy contribution of all the five frequency components (Fig. 3). We found similar results with the low and high-frequency component; 24-h SBP was significantly associated with a higher energy contribution of the low as well as the highfrequency component. Restriction of these analyses to the healthy subpopulation showed similar results (Figs 4 and 5).

Analysis with 24-h DBP, mean arterial pressure, or pulse pressure, instead of 24-h SBP, gave similar results, both in the study population and the analyses restricted to the healthy subpopulation (data not shown).

\section{Associations of the other cardiovascular risk factors with total skin microvascular flow motion energy and the skin microvascular flow motion components}

We found no significant associations of sex, fasting plasma glucose levels, total-to-HDL cholesterol ratio, or pack-years of smoking with total SMF energy, both in the study 
TABLE 1. Baseline characteristics of the study population and the healthy subpopulation in the total group and according to tertiles of total skin microvascular flow motion energy

\begin{tabular}{|c|c|c|c|c|c|c|c|c|}
\hline \multirow[b]{2}{*}{ Characteristic } & \multicolumn{4}{|c|}{ Study population } & \multicolumn{4}{|c|}{ Healthy subpopulation } \\
\hline & Total & T1 $(n=168)$ & T2 $(n=169)$ & T3 $(n=169)$ & Total & T1 $(n=64)$ & T2 $(n=65)$ & T3 $(n=64)$ \\
\hline Age (years) & $58.8 \pm 8.5$ & $56.5 \pm 8.9$ & $59.3 \pm 8.0$ & $60.2 \pm 8.1$ & $55.6 \pm 8.5$ & $53.4 \pm 8.5$ & $56.2 \pm 8.7$ & $57.3 \pm 8.5$ \\
\hline Sex (men) & $260(51.4)$ & $85(50.6)$ & $88(52.1)$ & $87(51.5)$ & $80(41.5)$ & $26(40.6)$ & $27(41.5)$ & $27(42.2)$ \\
\hline \multicolumn{9}{|l|}{ BMI categories } \\
\hline $\begin{array}{l}\text { Normal weight } \\
\quad\left(\mathrm{BMl}<25 \mathrm{~kg} / \mathrm{m}^{2}\right)\end{array}$ & $171(33.8)$ & $57(33.9)$ & $52(30.8)$ & $62(36.7)$ & $108(56.0)$ & $36(56.3)$ & $36(55.4)$ & $36(56.3)$ \\
\hline $\begin{array}{l}\text { Overweight (BMI } \geq 25 \text { to } \\
\left.<30 \mathrm{~kg} / \mathrm{m}^{2}\right)\end{array}$ & $243(48.0)$ & $83(49.4)$ & $80(47.3)$ & $80(47.3)$ & $85(44.0)$ & $28(43.8)$ & $29(44.6)$ & $28(43.8)$ \\
\hline Obese $\left(\mathrm{BMI} \geq 30 \mathrm{~kg} / \mathrm{m}^{2}\right)$ & $92(18.2)$ & $28(16.7)$ & 37 (21.9) & $27(16.0)$ & - & - & - & - \\
\hline \multicolumn{9}{|l|}{ Waist circumference } \\
\hline Men $(\mathrm{cm})$ & $100.3 \pm 10.5$ & $102.0 \pm 11.5$ & $99.7 \pm 9.8$ & $99.2 \pm 9.9$ & $94.1 \pm 7.4$ & $95.3 \pm 7.6$ & $94.0 \pm 7.8$ & $93.1 \pm 6.9$ \\
\hline Women $(\mathrm{cm})$ & $90.8 \pm 13.5$ & $91.7 \pm 15.8$ & $91.2 \pm 12.1$ & $89.4 \pm 12.4$ & $84.4 \pm 8.0$ & $85.1 \pm 7.7$ & $84.3 \pm 9.0$ & $83.9 \pm 9.0$ \\
\hline $\operatorname{HbA1c}(\%)$ & $5.9 \pm 0.8$ & $5.8 \pm 0.6$ & $5.9 \pm 0.6$ & $5.9 \pm 0.6$ & $5.5 \pm 0.3$ & $5.5 \pm 0.3$ & $5.5 \pm 0.4$ & $5.5 \pm 0.3$ \\
\hline $\begin{array}{l}\text { Fasting plasma glucose } \\
\qquad(\mathrm{mmol} / \mathrm{l})\end{array}$ & $5.9 \pm 1.4$ & $5.6 \pm 1.3$ & $5.8 \pm 1.0$ & $5.9 \pm 1.1$ & $5.1 \pm 0.4$ & $5.1 \pm 0.4$ & $5.2 \pm 0.4$ & $5.1 \pm 0.4$ \\
\hline Total cholesterol (mmol/l) & $5.4 \pm 1.1$ & $5.5 \pm 1.0$ & $5.4 \pm 1.2$ & $5.5 \pm 1.1$ & $5.7 \pm 1.0$ & $5.6 \pm 0.9$ & $5.6 \pm 1.0$ & $5.7 \pm 1.1$ \\
\hline HDL-cholesterol (mmol/l) & $1.4 \pm 0.4$ & $1.4 \pm 0.4$ & $1.4 \pm 0.4$ & $1.4 \pm 0.4$ & $1.5 \pm 0.4$ & $1.5 \pm 0.4$ & $1.5 \pm 0.4$ & $1.5 \pm 0.4$ \\
\hline LDL-cholesterol (mmol/l) & $3.4 \pm 1.0$ & $3.5 \pm 0.9$ & $3.4 \pm 1.0$ & $3.5 \pm 1.0$ & $3.7 \pm 0.9$ & $3.7 \pm 0.8$ & $3.7 \pm 0.9$ & $3.8 \pm 1.0$ \\
\hline Total-to-HDL cholesterol ratio & $4.2 \pm 1.3$ & $4.4 \pm 1.5$ & $4.2 \pm 1.1$ & $4.1 \pm 1.3$ & $4.1 \pm 1.2$ & $4.0 \pm 1.2$ & $4.1 \pm 1.2$ & $4.0 \pm 1.2$ \\
\hline Triglycerides (mmol/l) & $1.2[0.8-1.7]$ & $1.2[0.8-1.7]$ & $1.3[0.9-1.8]$ & $1.2[0.8-1.7]$ & $1.0[0.7-1.3]$ & $0.9[0.7-1.2]$ & $1.0[0.7-1.5]$ & $1.0[0.7-1.3]$ \\
\hline 24-h SBP (mmHg) & $119 \pm 12$ & $116 \pm 11$ & $120 \pm 13$ & $120 \pm 12$ & $113 \pm 9$ & $110 \pm 9$ & $114 \pm 9$ & $115 \pm 10$ \\
\hline 24-h DBP (mmHg) & $74 \pm 7$ & $74 \pm 7$ & $75 \pm 7$ & $74 \pm 7$ & $72 \pm 6$ & $71 \pm 6$ & $73 \pm 6$ & $73 \pm 7$ \\
\hline 24-h MAP (mmHg) & $93 \pm 9$ & $91 \pm 8$ & $93 \pm 9$ & $93 \pm 9$ & $89 \pm 7$ & $87 \pm 7$ & $90 \pm 7$ & $90 \pm 8$ \\
\hline 24-h heart rate (b.p.m.) & $70 \pm 9$ & $70 \pm 9$ & $71 \pm 8$ & $69 \pm 9$ & $69 \pm 8$ & $69 \pm 8$ & $69 \pm 8$ & $69 \pm 8$ \\
\hline \multicolumn{9}{|l|}{ Smoking } \\
\hline Never & $173(34.2)$ & $64(38.1)$ & $61(36.1)$ & $48(28.4)$ & $79(40.9)$ & $28(43.8)$ & $28(43.1)$ & $23(35.9)$ \\
\hline Former & $260(51.4)$ & $80(47.6)$ & $86(50.9)$ & $94(55.6)$ & $86(44.6)$ & $28(43.8)$ & $29(44.6)$ & $29(45.3)$ \\
\hline Current & $73(14.4)$ & $24(14.3)$ & $22(13.0)$ & $27(16.0)$ & $28(14.5)$ & $8(12.5)$ & $8(12.3)$ & $12(18.8)$ \\
\hline Pack-years of smoking & $14.0[5.0-27.9]$ & $14.3[4.0-25.5]$ & $15.3[6.0-30.4]$ & $11.8[4.9-31.0]$ & $10.5[4.2-25.7]$ & $14.5[3.8-25.5]$ & $12.8[4.4-27.4]$ & $7.8[4.9-24.4]$ \\
\hline \multicolumn{9}{|l|}{ Glucose metabolism } \\
\hline NGM & $297(58.7)$ & $110(65.5)$ & $95(56.2)$ & $92(54.4)$ & $193(100)$ & $64(100)$ & $65(100)$ & $64(100)$ \\
\hline IGM & $89(17.6)$ & $25(14.9)$ & $30(17.8)$ & $34(20.1)$ & - & - & - & - \\
\hline T2DM & $120(23.7)$ & $33(19.6)$ & $44(26.0)$ & $43(25.4)$ & - & - & - & - \\
\hline Hypertension & $189(37.4)$ & $61(36.3)$ & $70(41.4)$ & $58(34.4)$ & - & - & - & - \\
\hline $\begin{array}{c}\text { Peripheral sensory } \\
\text { neuropathy }{ }^{\mathrm{a}}\end{array}$ & $19(4.9)$ & $3(1.8)$ & $11(6.5)$ & $5(3.0)$ & $0(0)$ & $0(0)$ & $0(0)$ & $0(0)$ \\
\hline
\end{tabular}

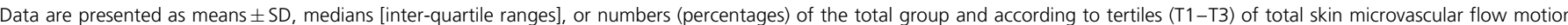
energy. HDL, high-density lipoprotein; LDL, low-density lipoprotein; MAP, mean arterial pressure; T2DM, type 2 diabetes mellitus. $P$ value for linear trend or $P$ value for linear-by-linear associations as appropriate.

aPSN measurements were based on data from only 391 of the 506 participants in the study population and 160 of the 193 participants in the healthy subpopulation.

population (Fig. 2) and the healthy subpopulation (Fig. 4). In addition, sex, fasting plasma glucose levels, total-to-HDL cholesterol ratio, or pack-years of smoking were not associated with a higher or lower energy contribution of the five SMF components (data not shown).

Analysis with HbA1c or diagnostic measures of T2DM [i.e. T2DM (yes/no), T2DM and insulin use (yes/no), T2DM and peripheral neuropathy (yes/no)] instead of fasting plasma glucose did not result in significant associations either (data not shown). Nevertheless, participants with a
T2DM duration of at least 10 years had a lower energy contribution of the endothelial component as compared to participants with a T2DM for less than 10 years [s $\beta-0.23 \mathrm{SD}$ $(-0.46,-0.01) ; P=0.04]$.

\section{Additional analyses}

First, the associations of the cardiovascular risk factors with both total SMF energy and the energy contribution of the components did not differ by diabetes status (data not shown). Second, the five SMF components can also be

TABLE 2. Flow motion in the study population and the healthy subpopulation

Characteristic

Total skin microvascular flow motion energy (A.U.)

Energy contribution endothelial component (A.U.)

Energy contribution neurogenic component (A.U.)

Energy contribution myogenic component (A.U.)

Energy contribution respiratory component (A.U.)

Energy contribution heart beat component (A.U.)
Study population $(n=506)$

$14.5[9.1-21.4]$

$0.9[0.5-1.4]$

$1.4[0.8-2.2]$

$1.4[0.8-2.2]$

$2.1[1.3-3.3]$

$8.2[4.8-12.1]$
Healthy subpopulation $(n=193)$

$13.6[7.8-22.1]$

$0.9[0.5-1.4]$

$1.3[0.8-2.2]$

$1.4[0.8-2.3]$

$1.9[1.2-3.2]$

$7.3[4.2-12.4]$

Data are presented as medians [inter-quartile ranges]. A.U., arbitrary units. 


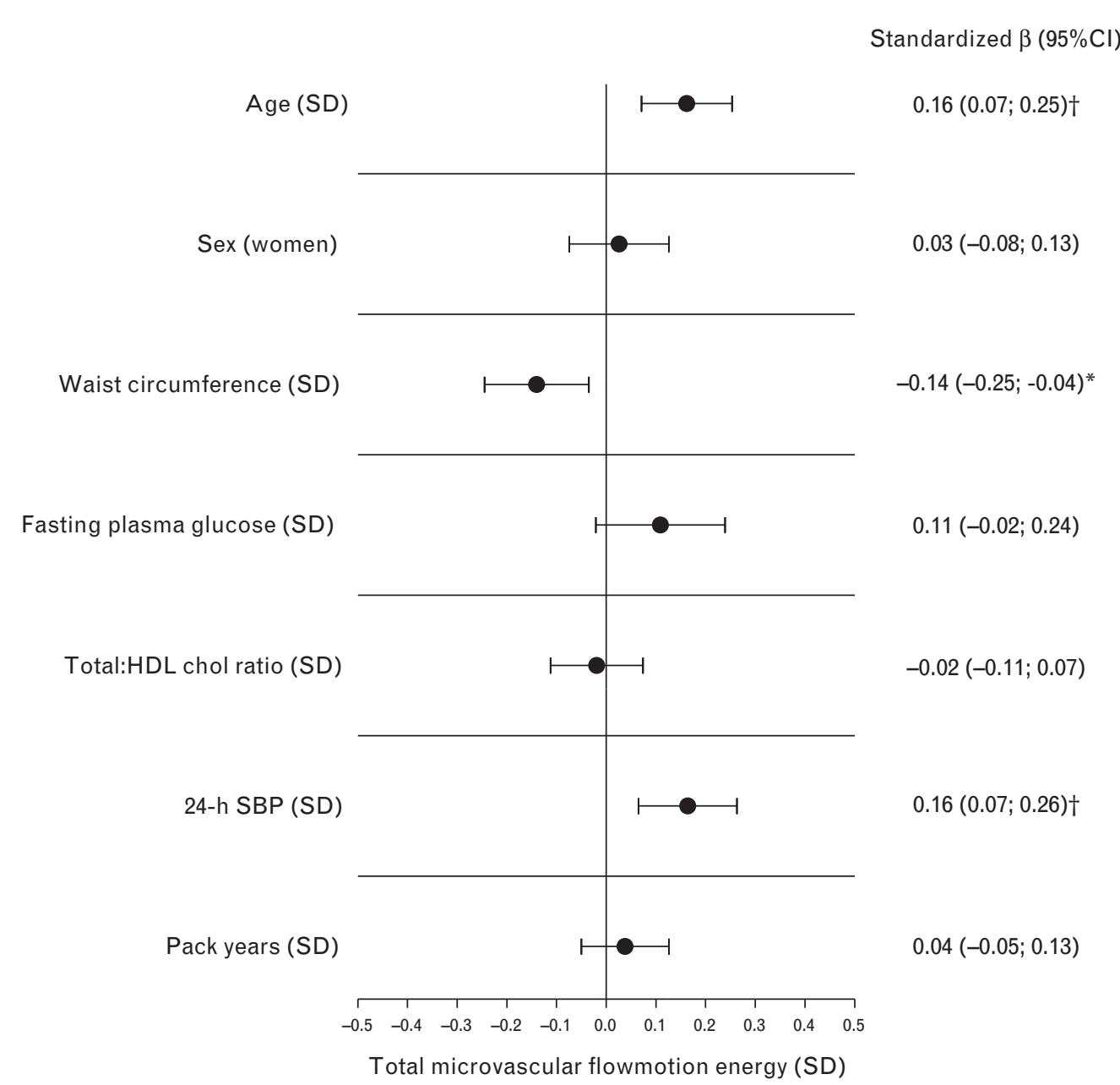

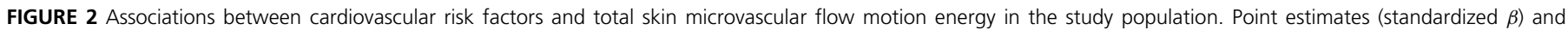

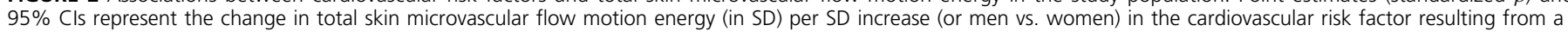
fully adjusted multivariate regression model. ${ }^{*} P<0.05 ; \dagger P<0.001 . \mathrm{Cl}$, confidence interval.

expressed in relative energy contributions [30]. Analysis with the relative energy contribution instead of absolute energy contribution of the SMF components demonstrated that age was associated with a lower relative energy contribution of the endothelial, neurogenic, and myogenic components, but with a higher relative energy contribution of both the respiratory and the heart beat component. In addition, waist circumference and 24-h SBP were not associated with a higher or lower relative energy contribution of the five SMF components (data not shown). Third, additional adjustment for time of LDF measurements (to adjust for diurnal influences) and time from light meal till LDF measurements (to adjust for light meal influences) gave similar results (data not shown). Fourth, additional adjustment for glucose-lowering medication, antihypertensive medication, and lipid-modifying medication use in the study population gave similar results (data not shown).

\section{DISGUSSION}

The study represents a comprehensive analysis of the associations of cardiovascular risk factors with SMF in a populationbased sample. The study had two main findings. First, age and 24-h SBP were directly, and waist circumference was inversely associated with SMF after adjustment for the other cardiovascular risk factors, diabetes status, glucose-lowering medication, antihypertensive medication, and lipid-modifying medication use. Second, these associations were similar both in the study population and in the healthy subpopulation. Importantly, the study population is likely to be representative of the source population in the study region (e.g. the prevalence of overweight, obesity, and hypertension was 48.0, 18.2, and 37.4\%, respectively, in our dataset as compared to $48.0,12.0$, and $31.4 \%$ in the general Dutch population [31,32]). However, since the Maastricht Study focuses on the cause, pathophysiology, complications and comorbidities of T2DM, recruitment was stratified according to known T2DM status [20]. Nevertheless, restriction of these analyses to the healthy subpopulation (without IGM and T2DM) showed similar results, indicating that these associations were not determined by IGM or T2DM and these associations can be considered valid for the general population.

Our finding that age and 24-h SBP were directly and that waist circumference was inversely associated with total SMF energy is in line with previous studies $[16,18,33,34]$. 


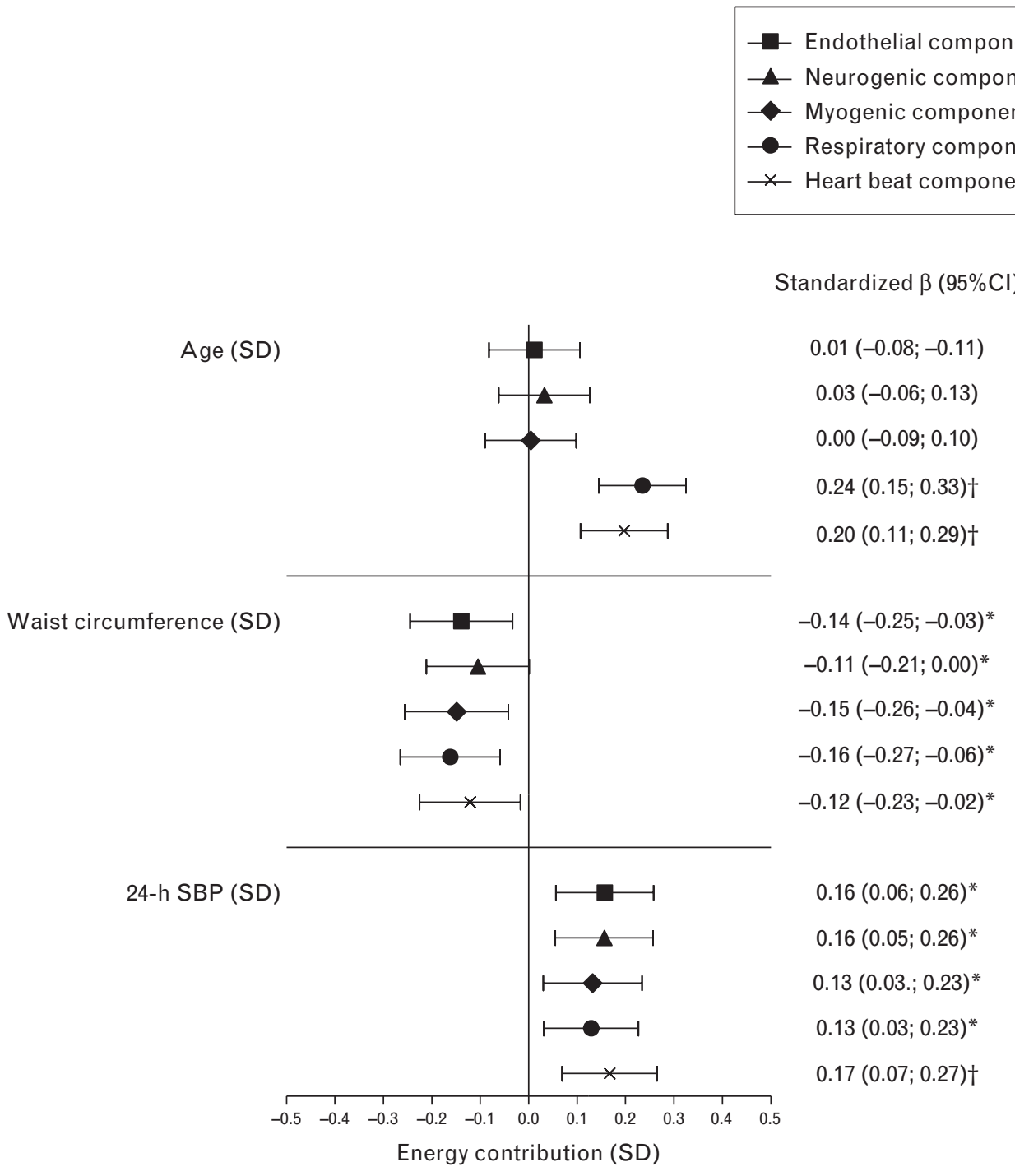

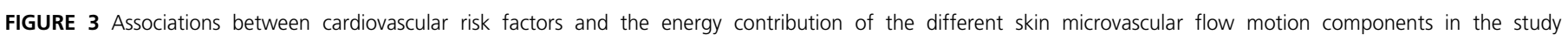
population. Point estimates (standardized $\beta$ ) and $95 \% \mathrm{Cls}$ represent the change in the energy contribution of the frequency component (in SD) per SD increase in the cardiovascular risk factor resulting from a fully adjusted multivariate regression model. ${ }^{*} P<0.05 ; \dagger P<0.001$. Cl, confidence interval.

Nevertheless, the age-related increases in the respiratory and heart beat component, the waist circumference-related decreases, and the BP-related increases in all the five frequency components demonstrated in our study somewhat contrast with findings of other studies which demonstrated age, obesity, and hypertension-related alterations in the low-frequency components $[16,18,34]$. The explanation for these discrepancies is not entirely clear, but may be related to the fact that we studied a larger group (i.e. we had more power to detect small differences) and previous studies investigated a non-random sample of the population which could have introduced selection bias.

There is convincing evidence that the regulation of whole body and tissue metabolism and BP by the microcirculation [14] may be mediated, at least partly, via effects on flow motion under both physiological and pathophysiological conditions [1,8]. Indeed, several studies demonstrated that insulin and meal ingestion stimulate microvascular flow motion, which is likely paralleled with an increased tissue perfusion and increased insulin-stimulated glucose uptake in skeletal muscle [1,35]. In addition, experimental data demonstrated that rabbits with microvascular flow motion had a $20 \%$ lower arterial pressure as compared to rabbits without flow motion [7]. Furthermore, tissue areas threatened by homeostatic and metabolic stress demonstrated enhanced flow motion [36]. In addition, patients with mild peripheral arterial occlusive disease are characterized by enhanced flow motion [37]. Interestingly, when these patients were divided into those exhibiting flow motion and those who did not, those with flow motion had significantly higher tissue oxygen levels than those patients without, despite similar blood flow [37]. Thus, considering the suggested role of flow motion, we may suppose that the positive association of age and 24-h SBP with total SMF energy could represent an adaptive response to ageing and increased $\mathrm{BP}$, with beneficial effects on tissue perfusion and local hydraulic resistance. It should, however, be kept in mind that the positive associations of 


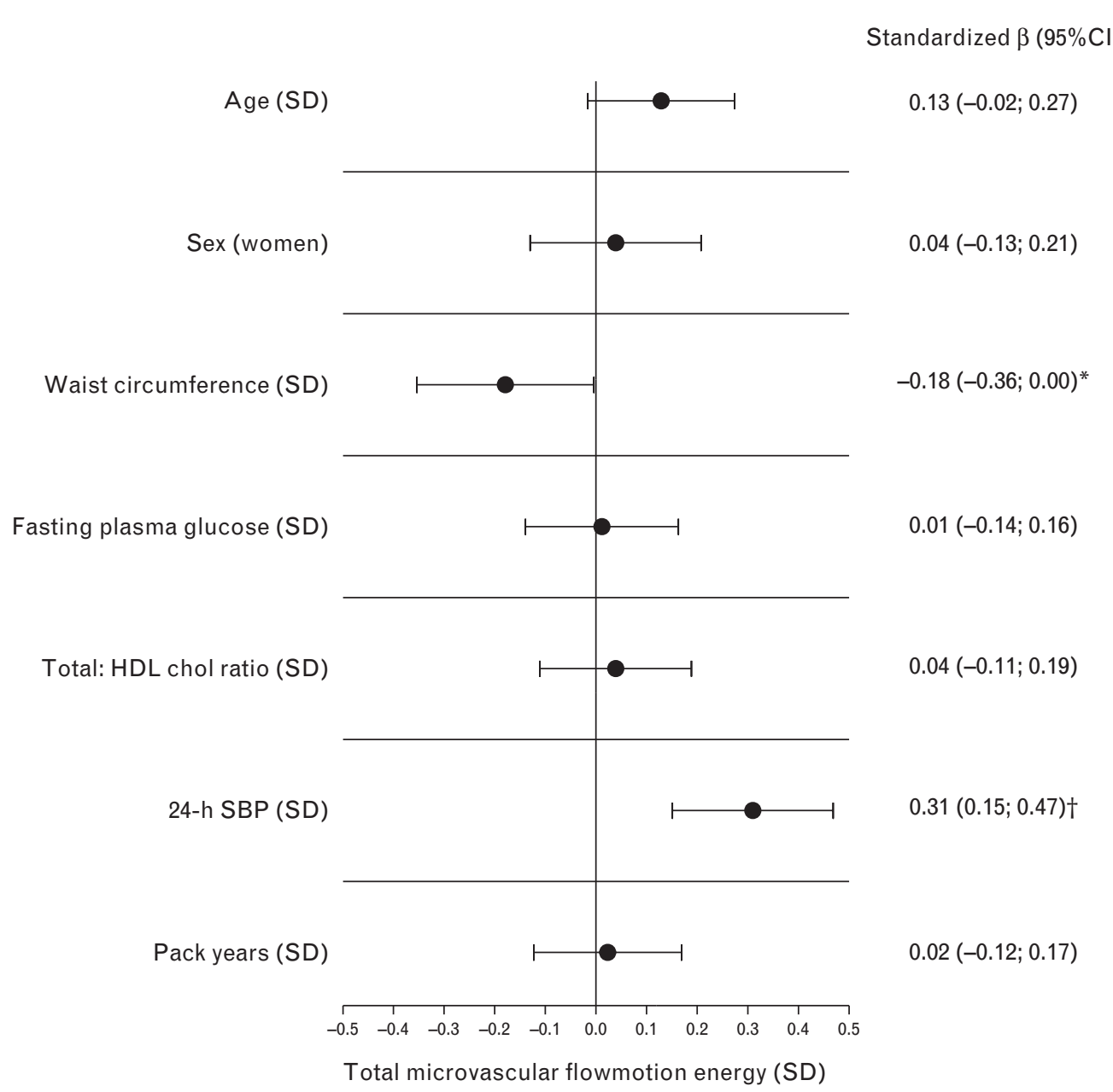

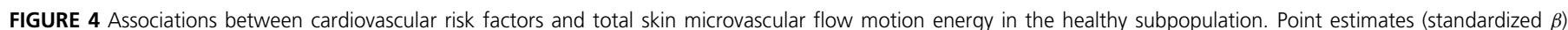
and $95 \%$ Cls represent the change in total skin microvascular flow motion energy (in SD) per SD increase (or men vs. women) in the cardiovascular risk factor resulting from a fully adjusted multivariate regression model. ${ }^{*} P<0.05 ; \dagger P<0.001$. Cl, confidence interval.

age and BP with SMF may reflect different aspects of microvascular function, which is reflected in the fact that we found positive associations of age with the high-frequency components and of BP with all frequency components. In addition, the negative association of waist circumference with total SMF energy could represent obesity-related disturbance of flow motion, with negative effects on the delivery of nutrients and oxygen to tissue and local hydraulic resistance, which is consistent with a role for microvascular dysfunction, specifically impaired SMF, in the development of obesity-related T2DM and hypertension [14].

Theoretical and experimental evidence for the concept that flow motion increases with age as an adaptive response is lacking. Hence, it should be realized that the positive association of age with SMF might be the consequence of a thinner epidermis with increased age, resulting in a greater measuring depth and thus increased perfusion signals. Nevertheless, studies investigating the effect of ageing on epidermal thickness demonstrated conflicting results [38,39], and therefore this concept remains controversial. In addition, increased perfusion signals due to a thinner epidermis would result in positive associations of all five frequency components. Here, we only demonstrated age-related increases of the respiratory and heart beat component, indicating that with ageing, there is a shift towards the contribution of the respiratory and heart beat component resulting in a, possibly adaptive, enhanced SMF.

With regard to BP, several experimental and mathematical models demonstrated that during $\mathrm{BP}$ elevations arterioles are constricted and an oscillating network can transiently dilate these arterioles, thereby increasing tissue perfusion and alter local hydraulic resistance [40,41]. Indeed, in the hamster microcirculation, vasoconstriction induced by $\mathrm{N}^{\mathrm{G}}$-monomethyl-L-arginine caused a decrease in effective diameter and an increase in flow motion frequency [41]. These experimental studies may support our finding of a positive association of $\mathrm{BP}$ with total SMF energy, indicating that flow motion may prevail over autoregulation during $\mathrm{BP}$ elevations [41]. In relation to the possible mechanisms involved, we demonstrated BPrelated increases in the energy contribution of all five frequency components. These findings suggest an improvement in the efficiency of all components of flow motion during BP elevation [18]. 


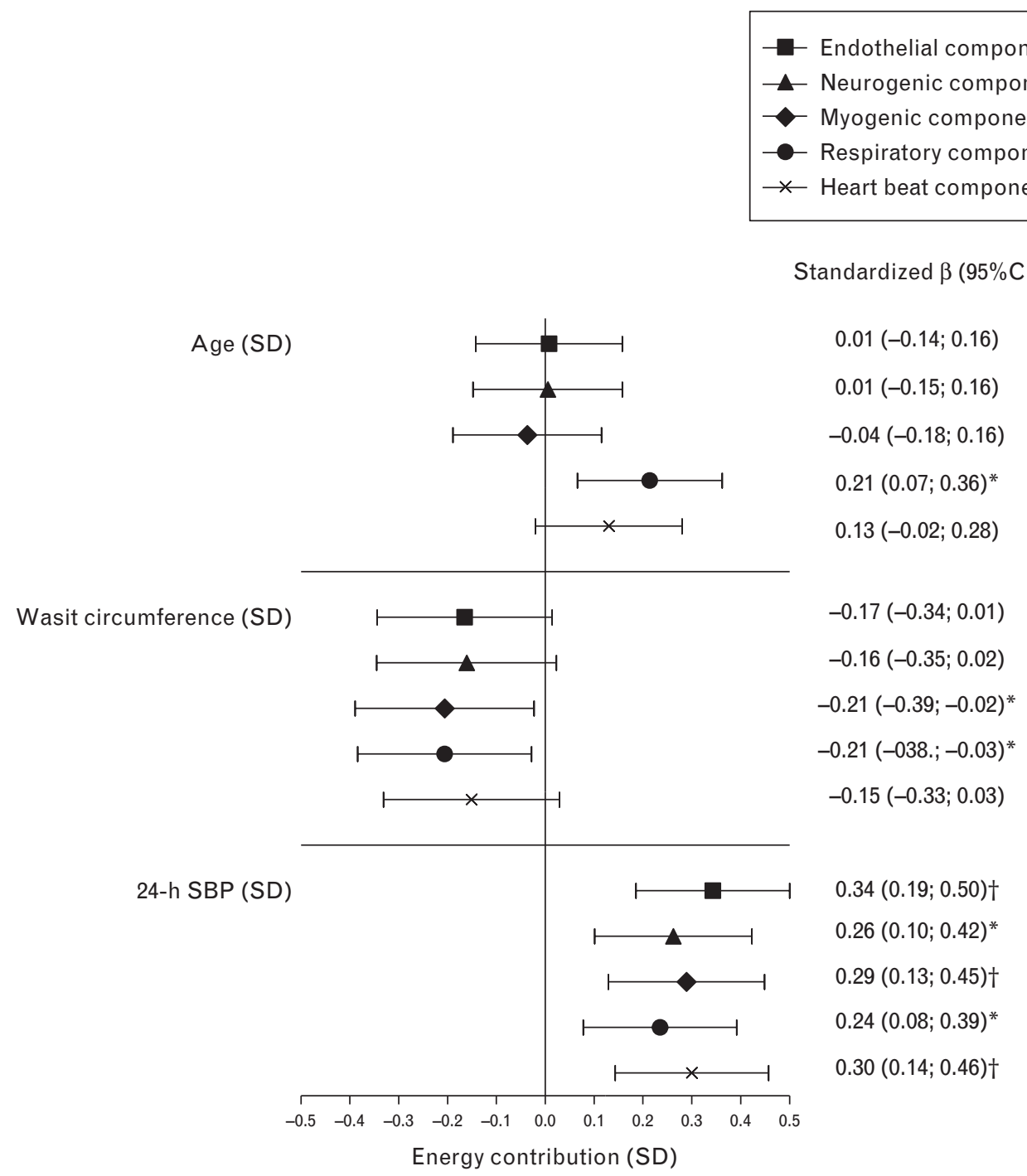

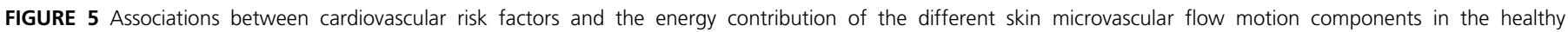

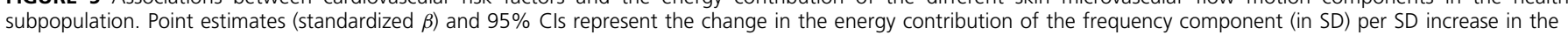
cardiovascular risk factor resulting from a fully adjusted multivariate regression model. ${ }^{*} P<0.05 ; \dagger P<0.001$. Cl, confidence interval.

With regard to waist circumference, there is convincing evidence that obesity is a primary cause of microvascular dysfunction [13] and that microvascular dysfunction, in turn, may be an intermediate step linking obesity to T2DM and hypertension [14]. In relation to the possible mechanisms involved, there is an increase in several circulating adipose tissue-derived factors in obesity, whereas the anti-inflammatory adipokine, adiponectin, is decreased. These endocrine factors are likely candidates to influence microvascular function and thus flow motion $[1,14]$. Hence, the waist circumference-related decreases in the energy contribution of all five frequency components may reflect a decline in the efficiency of all the components of flow motion due to these endocrine factors. Interestingly, major weight loss in severely obese patients resulted in a full normalization of flow motion [33], suggesting a causeeffect relationship between obesity and impaired flow motion.

The lack of a significant association of fasting plasma glucose and other metabolic or diagnostic measures of
T2DM with SMF was unexpected. Other studies suggested that humans with T1DM and T2DM are characterized by decreased flow motion patterns in the low-frequency oscillations $[15,17]$. The explanation for this discrepancy is not entirely clear, but may be related to the fact that the participants with T2DM in our study had a shorter diabetes duration [median of 7.0 (inter-quartile range 3.0-11.0) years] than in the other study (mean of $17.1 \pm 2.3$ years) [17]. Indeed, in the current study, participants with a T2DM duration of at least 10 years had a decreased energy contribution of the endothelial component as compared to participants with a T2DM for less than 10 years, suggesting that the altered patterns of flow motion as demonstrated in diabetes may be a complication of longstanding diabetes.

Sex, total-to-HDL ratio, and smoking are associated with macrovascular dysfunction [42]. However, we could not confirm these associations with SMF. Interestingly, several other studies did not find significant associations of sex, cholesterol, and smoking with measures of microvascular 
function either (i.e. skin capillary recruitment [43], and generalized retinal arteriolar narrowing and venular dilatation $[44,45])$, suggesting that these determinants are less important for microvascular as compared to macrovascular functioning.

The present study had some limitations. First, this study is cross-sectional in nature and therefore it is not possible to distinguish between cause and effect. Hence, further largescale (longitudinal) studies in this area are needed. Second, observational studies like the Maastricht Study do not allow invasive measurements (i.e. we studied skin and not muscle microcirculation). Nevertheless, several studies have demonstrated comparable metabolic [46] and vascular effects in skin and muscle [47]. These studies strongly suggest that vascular responses observed in skin are parallel to those in muscle, and thus that measurement of the skin microvasculature is a valid tool for the assessment of microvascular function [48]. Third, 86\% of all participants complied with the smoking, caffeine, and meal instructions before SMF measurements. However, when analyses were restricted to these participants, results did not change.

In conclusion, age and 24-h SBP are directly, and waist circumference is inversely associated with SMF in the general population. The exact mechanisms underlying these findings remain elusive. We hypothesize that flow motion may be an important component of the microcirculation by ensuring optimal delivery of nutrients and oxygen to tissue and regulate local hydraulic resistance not only under physiological conditions but also under pathophysiological conditions when microcirculatory perfusion is reduced, such as that which occurs with ageing and higher BP. In addition, obesity may result in an impaired flow motion with negative effects on the delivery of nutrients and oxygen to tissue and local hydraulic resistance.

\section{AGKNOWLEDGEMENTS}

Sources of funding: This research was supported by Maastricht University Medical Centre (MUMC+).

The Maastricht Study is supported by the European Regional Development Fund as part of OP-ZUID, the province of Limburg, the department of Economic Affairs of the Netherlands (grant 31O.041), Stichting the Weijerhorst, the Pearl String Initiative Diabetes, the Cardiovascular Center Maastricht, Cardiovascular Research Institute Maastricht (CARIM), School for Nutrition, Toxicology and Metabolism (NUTRIM), Stichting Annadal, Health Foundation Limburg and by unrestricted grants from Janssen, Novo Nordisk and Sanofi. RHZ foundation (Vereniging Regionale HuisartsenZorg Heuvelland) is gratefully acknowledged for their contribution to the Maastricht Study, enabling the invitation of individuals with T2DM by using information from their web-based electronic health record.

\section{Conflicts of interest}

There are no conflicts of interest.

\section{REFERENGES}

1. Jonk AM, Houben AJ, Schaper NC, de Leeuw PW, Serne EH, Smulders YM, Stehouwer CD. Meal-related increases in microvascular vasomotion are impaired in obese individuals: a potential mechanism in the pathogenesis of obesity-related insulin resistance. Diabetes Care 2011; 34 (Suppl 2):S342-S348.

2. Rattigan S, Clark MG, Barrett EJ. Hemodynamic actions of insulin in rat skeletal muscle: evidence for capillary recruitment. Diabetes 1997; 46:1381-1388.

3. Thorn CE, Kyte H, Slaff DW, Shore AC. An association between vasomotion and oxygen extraction. Am J Physiol Heart Circ Physiol 2011; 301:H442-449.

4. Ursino M, Cavalcanti S, Bertuglia S, Colantuoni A. Theoretical analysis of complex oscillations in multibranched microvascular networks. Microvasc Res 1996; 51:229-249.

5. Intaglietta M. Vasomotion and flowmotion: physiological mechanisms and clinical evidence. Vasc Med 1990; 1:101-112.

6. Slaaf DW, Vrielink HH, Tangelder GJ, Reneman RS. Effective diameter as a determinant of local vascular resistance in presence of vasomotion. Am J Physiol 1988; 255:H1240-H1243.

7. Schmidt-Lucke C, Borgstrom P, Schmidt-Lucke JA. Low frequency flowmotion/(vasomotion) during patho-physiological conditions. Life Sci 2002; 71:2713-2728.

8. Aalkjaer C, Boedtkjer D, Matchkov V. Vasomotion: what is currently thought? Acta Physiol (Oxf) 2011; 202:253-269.

9. Kvandal P, Stefanovska A, Veber M, Kvernmo HD, Kirkeboen KA. Regulation of human cutaneous circulation evaluated by laser Doppler flowmetry, iontophoresis, and spectral analysis: importance of nitric oxide and prostaglandines. Microvasc Res 2003; 65:160-171.

10. Stefanovska A, Bracic M, Kvernmo HD. Wavelet analysis of oscillations in the peripheral blood circulation measured by laser Doppler technique. IEEE Trans Biomed Eng 1999; 46:1230-1239.

11. Manson JE, Nathan DM, Krolewski AS, Stampfer MJ, Willett WC, Hennekens $\mathrm{CH}$. A prospective study of exercise and incidence of diabetes among US male physicians. JAMA 1992; 268:63-67.

12. Muris DM, Houben AJ, Schram MT, Stehouwer CD. Microvascular dysfunction is associated with a higher incidence of type 2 diabetes mellitus: a systematic review and meta-analysis. Arterioscler Thromb Vasc Biol 2012; 32:3082-3094.

13. de Jongh RT, Serne EH, IJzerman RG, de Vries G, Stehouwer CD. Impaired microvascular function in obesity: implications for obesityassociated microangiopathy, hypertension, and insulin resistance. Circulation 2004; 109:2529-2535.

14. Muris DM, Houben AJ, Schram MT, Stehouwer CD. Microvascular dysfunction: an emerging pathway in the pathogenesis of obesityrelated insulin resistance. Rev Endocr Metab Disord 2013; 14:29-38.

15. Benbow SJ, Pryce DW, Noblett K, MacFarlane IA, Friedmann PS, Williams G. Flow motion in peripheral diabetic neuropathy. Clin Sci (Lond) 1995; 88:191-196.

16. de Jongh RT, Serné EH, IJzerman RG, Jørstad HT, Stehouwer CD. Impaired local microvascular vasodilatory effects of insulin and reduced skin microvascular vasomotion in obese women. Microvasc Res 2008; 75:256-262.

17. Stansberry KB, Shapiro SA, Hill MA, McNitt PM, Meyer MD, Vinik AI Impaired peripheral vasomotion in diabetes. Diabetes Care 1996; 19:715-721.

18. Rossi M, Bradbury A, Magagna A, Pesce M, Taddei S, Stefanovska A. Investigation of skin vasoreactivity and blood flow oscillations in hypertensive patients: effect of short-term antihypertensive treatment. J Hypertens 2011; 29:1569-1576.

19. Rossi M, Carpi A, Di Maria C, Galetta F, Santoro G. Absent postischemic increase of blood flowmotion in the cutaneous microcirculation of healthy chronic cigarette smokers. Clin Hemorheol Microcirc 2007; 36:163-171.

20. Schram MT, Sep SJ, Kallen van der CJ, Dagnelie PC, Koster A, Schaper NC, et al. The Maastricht Study: an extensive phenotyping study on determinants of type 2 diabetes, its complications and its comorbidities. Eur J Epid 2014; 29:439-451.

21. Braverman IM, Schechner JS, Silverman DG, Keh-Yen A. Topographic mapping of the cutaneous microcirculation using two outputs of laserDoppler flowmetry: flux and the concentration of moving blood cells Microvasc Res 1992; 44:33-48.

22. Kvandal P, Landsverk SA, Bernjak A, Stefanovska A, Kvernmo HD, Kirkeboen KA. Low-frequency oscillations of the laser Doppler perfusion signal in human skin. Microvasc Res 2006; 72:120-127.

23. Pencina MJ, D’Agostino RB Sr, Larson MG, Massaro JM, Vasan RS. Predicting the 30-year risk of cardiovascular disease: the framingham heart study. Circulation 2009; 119:3078-3084. 
24. WHO. Definition and Diagnosis of diabetes mellitus and intermediate hyperglycemia; 2006. www.who.int/diabetes/publications/Definition\%20and\%20diagnosis\%20of\%20diabetes_new.pdf.

25. O'Brien E, Coats A, Owens P, Petrie J, Padfield PL, Littler WA, et al. Use and interpretation of ambulatory blood pressure monitoring: recommendations of the British hypertension society. BMJ 2000; 320:11281134.

26. Chobanian AV, Bakris GL, Black HR, Cushman WC, Green LA, Izzo JL $\mathrm{Jr}$, et al. Seventh report of the Joint National Committee on Prevention, Detection, Evaluation, and Treatment of High Blood Pressure. Hypertension 2003; 42:1206-1252.

27. Boulton AJ, Malik RA, Arezzo JC, Sosenko JM. Diabetic somatic neuropathies. Diabetes Care 2004; 27:1458-1486.

28. Karvestedt L, Martensson E, Grill V, Elofsson S, von Wendt G, Hamsten A, Brismar K. Peripheral sensory neuropathy associates with micro- or macroangiopathy: results from a population-based study of type 2 diabetic patients in Sweden. Diabetes Care 2009; 32:317-322.

29. Soper DS. A-priori sample size calculator for multiple regression [software]; 2014. http://www.danielsoper.com/statcalc.

30. Bracic M, Stefanovska A. Wavelet-based analysis of human blood-flow dynamics. Bull Math Biol 1998; 60:919-935.

31. Bakel AM, Zantinge EM. Neemt het aantal mensen met overgewicht toe of af? In Volksgezondheid Toekomst Verkenning, Nationaal Kompas Volksgezondheid. Bilthoven: RIVM, <http://www.nationaalkompas.nl> Nationaal Kompas Volksgezondheid $\backslash$ Determinanten $\backslash$ Persoonsgebonden $\backslash$ Overgewicht, 25 September 2013.

32. Blokstra A, Bakel AM. Hoeveel mensen hebben een verhoogde bloeddruk? In Volksgezondheid Toekomst Verkenning, Nationaal Kompas Volksgezondheid. Bilthoven: RIVM, <http://www.nationaalkompas.nl> Nationaal Kompas Volksgezondheid $\backslash$ Determinanten $\backslash$ Persoonsgebon den $\backslash$ Bloeddruk, 7 December 2012.

33. Rossi M, Nannipieri M, Anselmino M, Pesce M, Muscelli E, Santoro G, Ferrannini E. Skin vasodilator function and vasomotion in patients with morbid obesity: effects of gastric bypass surgery. Obes Surg 2011; 21:87-94.

34. Tikhonova IV, Tankanag AV, Chemeris NK. Age-related changes of skin blood flow during postocclusive reactive hyperemia in human. Skin Res Technol 2013; 19:e174-e181.

35. Newman JM, Dwyer RM, St-Pierre P, Richards SM, Clark MG, Rattigan S. Decreased microvascular vasomotion and myogenic response in rat skeletal muscle in association with acute insulin resistance. $J$ Physiol 2009; 587:2579-2588.

\section{Reviewers' Summary Evaluations}

\section{Reviewer 1}

This study provides data on skin microvascular flow motion recorded by Laser-Doppler-flowmetry (LDF) in a relatively large study population. Positive correlations for the power in the LDF signal vs. age and arterial pressure and a negative correlation for the power of the LDF signal vs. waist circumference are reported. The strengths of the study are the large sample investigated and the consistency of data obtained in the entire study population and in a healthy subpopulation, excluding confounding treatment effects on the observed relationships between
36. Bertuglia S, Colantuoni A, Coppini G, Intaglietta M. Hypoxia- or hyperoxia-induced changes in arteriolar vasomotion in skeletal muscle microcirculation. Am J Physiol 1991; 260:H362-H372.

37. Schmidt JA. Periodic hemodynamics in health and disease. Georgetown: R.G. Landes Company; 1996.

38. Branchet MC, Boisnic S, Frances C, Robert AM. Skin thickness changes in normal aging skin. Gerontology 1990; 36:28-35.

39. Sandby-Moller J, Poulsen T, Wulf HC. Epidermal thickness at different body sites: relationship to age, gender, pigmentation, blood content, skin type and smoking habits. Acta Derm Venereol 2003; 83:410-413.

40. Rucker M, Strobel O, Vollmar B, Roesken F, Menger MD. Vasomotion in critically perfused muscle protects adjacent tissues from capillary perfusion failure. Am J Physiol Heart Circ Physiol 2000; 279:H550H558.

41. Ursino M, Colantuoni A, Bertuglia S. Vasomotion and blood flow regulation in hamster skeletal muscle microcirculation: A theoretical and experimental study. Microvasc Res 1998; 56:233-252.

42. Iwamoto Y, Maruhashi T, Fujii Y, Idei N, Fujimura N, Mikami S, et al. Intima-media thickness of brachial artery, vascular function, and cardiovascular risk factors. Arterioscler Thromb Vasc Biol 2012; 32:22952303.

43. IJzerman RG, de Jongh RT, Beijk MA, van Weissenbruch MM, Delemarre-van de Waal HA, Serne EH, Stehouwer CD. Individuals at increased coronary heart disease risk are characterized by an impaired microvascular function in skin. Eur J Clin Invest 2003; $33: 536-542$

44. Kawasaki R, Tielsch JM, Wang JJ, Wong TY, Mitchell P, Tano Y, et al. The metabolic syndrome and retinal microvascular signs in a Japanese population: the Funagata study. Br J Ophthalmol 2008; 92:161-166.

45. Wong TY, Duncan BB, Golden SH, Klein R, Couper DJ, Klein BE, et al. Associations between the metabolic syndrome and retinal microvascular signs: the Atherosclerosis Risk In Communities study. Invest Ophthalmol Vis Sci 2004; 45:2949-2954.

46. Lang $\mathrm{CH}$. Rates and tissue sites of noninsulin- and insulin-mediated glucose uptake in diabetic rats. Proc Soc Exp Biol Med 1992; 199:81-87.

47. Meijer RI, De Boer MP, Groen MR, Eringa EC, Rattigan S, Barrett EJ, et al. Insulin-induced microvascular recruitment in skin and muscle are related and both are associated with whole-body glucose uptake. Microcirculation 2012; 19:494-500.

48. Gronenschild EH, Muris DM, Schram MT, Karaca U, Stehouwer CD, Houben AJ. Semi-automatic assessment of skin capillary density: Proof of principle and validation. Microvasc Res 2013; 90:192-198.

cardiovascular risk factors and skin microvascular flow motion. Mechanistic insights on microcirculatory function are limited.

\section{Reviewer 2}

This is a cross-sectional study, which investigated the association between cardiovascular risk factors and skin microvascular flow motion. The study being crosssectional, caution is needed in consideration of any causal relationship. The clinical importance and significance of skin microvascular flow motion remains to be investigated in future large studies. 